•保护论坛・

\title{
生态保护红线修复机制法治化: 定位、困境及其出路
}

\author{
莫张勤 \\ (浙江大学光华法学院, 杭州 310000)
}

\begin{abstract}
摘要: 生态保护红线以生态系统的完整性、生态系统服务功能的一致性与生态空间的连续性为核心, 致力于保护 国家的生态安全。生态保护红线修复分区分类展开, 以修复受损生态系统为目标, 具有自然修复和社会修复双重 内涵。生态保护红线存在脆弱性、敏感性、复杂性与极易破坏性等特征, 它在建立修复机制法治化过程中遇到空 间不可置换、治理费用高昂和治理主体责任错乱等困境。生态保护红线修复机制应建立“明确预防为主原则为指 导、成立修复专项资金为手段、确定修复主体顺位为责任保障”的法治化的基本路径, 以实现重要生态系统保护和 修复重大工程, 构建生态廊道和生物多样性保护网络。
\end{abstract}

关键词: 生态修复; 生态保护红线; 生态安全; 预防为主原则

\section{Re-legalizing China's ecological conservation redline: The position, dilemma and path}

\author{
Zhangqin $\mathrm{Mo}^{*}$ \\ Guanghua Law School, Zhejiang University, Hangzhou 310000
}

\begin{abstract}
The ecological conservation redline centers on protecting the integrity and continuity of the ecosystem and the consistency of ecosystem service functions. Overall, the policy is committed to protecting the country's ecological security. Re-instating the ecological conservation redline should assist in targeting the restoration of damaged ecosystem, in the context of both natural and social restoration. The ecological conservation redline has characteristics of the vulnerability, sensitivity, complexity and extreme destructibility of ecosystems. It has problems such as the irreplaceable space, high governance costs, and chaotic governance responsibility on the path of establishing legalization of repairing mechanism. According to the base rule of legalization, a core system should be established through clarifying the principle of prevention as the main guide, establishing special funds for repair, and determining the responsibility of repairing the subject as the responsibility guarantee, to achieve the environmental goal of protecting and restoring key ecosystem and developing ecological corridors and biodiversity protection networks.
\end{abstract}

Key words: ecological restoration; ecological conservation redline; ecological security; precautionary principle

2018年8月28日，全国首例野生动物保护预防 性环境民事公益诉讼在昆明市中级人民法院开庭 审理。原告(北京市朝阳区自然之友环境研究所)认 为被告(新平公司和昆明勘查设计研究院有限公司) 在生态保护红线范围内建设水电站将会对绿孔雀 (Pavo muticus)这一国家一级保护动物的栖息地造
成淹没并导致绿孔雀区域性灭绝。此外，戛酒江水 电站建设施工和淹没区域的生态价值极高, 生物多 样性极其丰富，水电站建成后会对国家重点保护植 物陈氏苏铁(Cycas chenii) 以及热带雨林造成重大损 害风险, 基于此, 原告请求法院判令被告立即停止 对水电站的建设。此案件引起了高度关注, 在生态 
红线保护与修复机制法治化过程中起到了推动作 用。

\section{生态保护红线修复机制法治化的}

\section{1 生态保护红线的分类与修复范围}

国际上通行的做法是将天然或近天然的区域 划作保护地，建立生态空间体系对物种及其生境进 行保护(刘冬等, 2015)。我国生态保护红线(简称生 态红线) 是在新时代背景下制定的与生态文明相适 应的创新制度，体现了国家以强制手段强化生态保 护的决心和政策导向。

2017年中共中央办公厅、国务院办公厅印发 《关于划定并严守生态保护红线的若干意见》(以下 简称《若干意见》)规定, “生态保护红线是指在生态 空间范围内具有特殊重要生态功能, 必须强制严格 保护的区域，是保障和维护国家生态安全的底线和 生命线。通常包括具有重要水源涵养, 生物多样性 保护……”。它可划分为重点生态功能区、生态敏 感区、脆弱区、禁止开发区等区域，实行分区分类 管理(邹长新等, 2015)。重点生态功能区的生态系统 具有举足轻重的地位, 其生态恢复能力较强, 限制 程度较低。生态敏感区受外界干扰强, 容易受到人 类活动影响, 生态恢复能力较弱, 原则上禁止开发 利用。生态脆弱区与禁止开发区的生态系统组成结 构不稳定，自我恢复能力弱，禁止开发利用。

《若干意见》第11条规定, “实施生态保护红线 保护与修复, 作为山水林田湖生态保护与修复工程 的重要内容。优先保护良好生态系统和重要物种栖 息地, 建立和完善生态廊道, 提高生态系统完整性
和连通性。分区分类开展受损生态系统修复, 采取 封禁为主的自然恢复措施, 辅以人工修复, 改善和 提升生态功能”。生态保护红线管理的目标是以生 态系统为导向，尽可能地减少生态系统损害并降低 生态环境风险，预防人类行为对生态保护红线产生 不必要的干扰和生态损害的风险(杨治坤, 2017)。根 据生态保护红线的主要类型及其生态恢复能力、限 制程度，对于良好生态系统和重要物种栖息地应优 先保护; 对于受损生态系统应分区分类进行修复， 整体以封禁为主的自然修复为原则，以人工修复为 辅。如生态敏感区和生态脆弱区、禁止开发区的生 态恢复能力较弱, 一旦生态退化, 自然恢复困难, 需要人工辅助修复, 修复机制的规范化和法治化具 有重要的现实意义(图1)。对于优良生态系统服务功 能的保护问题已有较多文献进行研究，但对于红线 区生态系统退化如何修复的问题关注较少，在实践 中出现较多问题，亟需法律层面的回应。

\section{2 生态保护红线修复机制法治化功能定位}

生态保护红线的划定是根据国家或区域生态 系统状况、功能和特征, 在充分考虑生态系统完整 性和稳定性的基础上，结合国家和区域经济发展需 要, 对特殊地区划定边界的过程(施业家和吴贤静, 2016)。“生态系统”是生态保护红线划定的考虑基础, 也是修复过程中的考量标准。生态保护红线修复机 制是指通过人工治理或重建举措逐步恢复红线区 已退化的生态系统，在合理分配社会资源基础上， 实现人与自然的和谐共处并整体实现国家生态安 全的系统工程。它主要着重以下方面:

(1)修复红线区生态系统和重要物种栖息地。生

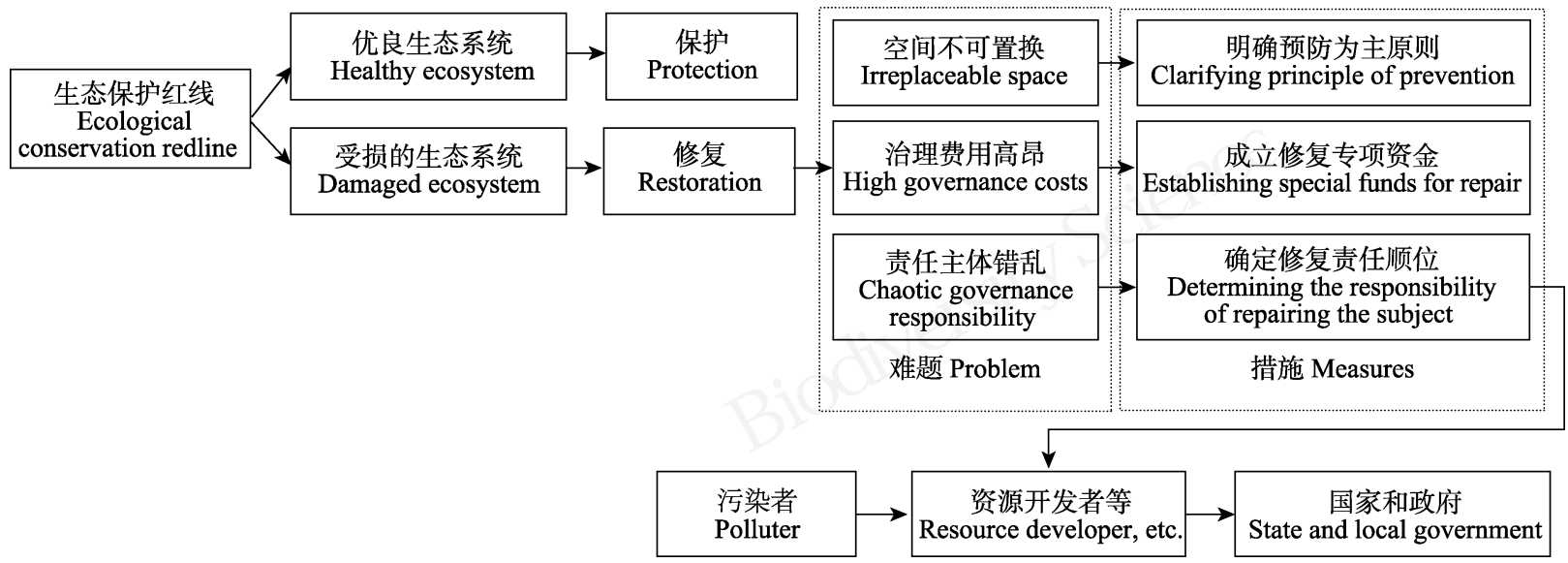

图1 生态保护红线修复机制法治化整体思路

Fig.1 The overall structure path of legalization of restoration mechanism of ecological conservation redline 
态保护红线关注生态系统内部及其与外部各要素 之间的关系和各项功能, 构建生态廊道和生物多样 性保护网络。传统的观点大多片面强调生态系统的 经济价值，而经济价值一般通过简单地使用金钱就 可得到恢复, 但生态系统损害修复必须着眼于生态 系统这个宏观整体，依靠生态环境的自我调节、自 我组织进而实现自体恢复。生态系统服务产生的生 态过程、相互关系及其驱动因素, 为红线区生态系 统服务的发挥和优化管理提供了科学依据(高吉喜, 2015)。红线区生态功能修复注重原有的区域生态服 务功能的修复, 即充分尊重、发挥某种生态要素与 其他生态要素间的相互联系与相互作用, 本质上体 现为事物之间供养支持的相互关系。

(2)减少因自然生态系统而引发的人与自然及 人类自身关系的传导性损害。前者包含原住民因生 态保护红线划定被迫离开家园, 失去了生产生活资 料, 无法生存; 后者体现为污染施加方与环境受害 者之间的矛盾对立、生态保护红线所在地的政府与 群众关系恶化。因此, 这种生态修复通过环境正义 的手段体现了对社会正义的探索。

生态保护红线修复机制法治化是法治完善状 态下生态修复法制的有效运作(吴鹏, 2013)。它包 含 自然修复和社会修复双重内涵。从自然修复角度而 言，依靠人类治理手段协助红线区生态系统实现自 我复原, 或者兴建生态修复建设工程推动生态系统 重新达到平衡。如禁止开发区限制人类活动, 利用 自然的承载力与自净能力达到红线区生态的持续 循环运转及平衡。

从社会修复角度而言, 经过公平划分生态修复 中各主体的权利与义务, 协调不同区域、不同社会 成员间资源的再分配，以构建合理化生态修复责任 承担机制来推进环境公平、社会可持续发展的过 程。实现生态修复法治化, 其核心价值在于以公平 合理划分法律责任承担标准达到社会主体间经济 利益的再分配，进而实现环境利益的分配正义价值， 彰显环境正义。生态保护红线修复机制通过社会修 复实现分配正义, 用生态修复法治手段确保分配正 义价值的有效表达。分配正义正是社会经济发展(财 富与福利)标准的规范化法律表达形式。生态保护 红线修复机制法治化使国内不同地区实现生存权 与发展权的平等分配, 进而实现财富与福利等相关 经济利益的公平分配, 促进环境、经济、社会协调
发展。

因此，实现生态保护红线修复机制的法治化， 须构建生态利益、经济利益和社会利益和谐发展的 多元法益体系，遵循以生态利益为首位，以经济利 益为补充, 以社会利益为归宿的价值追求。对红线 区的修复，既要恢复已受到破坏的生态系统，也须 正视因自然环境受损而造成的人与自然人与人之 间关系的损害，提前预见相关利害关系人对治理方 案甄选、执行中的利益诉求及修复标准的选择，全 面统筹, 深入贯彻以生态环境保护为第一位，兼 顾、允许、尊重、促进生态好转所衍生的经济利益 和社会效益(魏旭, 2016)。在实现修复自然环境的同 时，也逐步建立人类社会与环境之间的良性互动、 互为供养的循环机制。

\section{生态保护红线修复机制法治化的}

\section{1 空间不可替换增加修复难度}

2014 年《关于“十三五”市县经济社会发展规划 改革创新的指导意见》规定我国国土空间可分为城 镇空间、农业空间和生态空间。生态空间是生态保 护红线的上位概念, 以提供生态产品与生态服务为 主要特色与功能的国土空间。它依据“生态底线”导 向的直接管制作用机理，可以分为生态保护红线和 弹性生态空间。二者的区别在于，弹性生态空间与 其他空间可以相互转换(沈悦等, 2017)。而生态保护 红线从定义来看，必须是空间意义上的划分，是依 据国家统一的技术性规范而达成的、地理意义上的 划线。生态保护红线的自然生态用地不可转换成非 生态用地，它的边界保持相对固定，区域面积规模 不可随意减少，它不具有空间置换性的问题，特别 是重要物种栖息地较难空间互换。

因此, 生态保护红线与耕地红线不同, 它的保 护对象与空间边界相对固定, 不能随意更改, 更改 必须经过国务院审批。生态保护红线划定时须全局 考虑全国与区域生态系统以及人类与生态环境的 相互作用, 同时将生态自身变化与人为造成的生态 系统退化加以区分以明晰生态系统保护区。生态红 线的管理工作也应依据生态系统的特点、功能定 位、恢复能力制定相应的管理规范，适用综合生态 系统方法应对人类活动对生态系统的干扰与影响。 生态保护红线的空间不可替换性给其修复工作加 大了难度。 


\section{2 治理费用高昂加重修复困境}

在漫长的诉讼或处罚当中, 红线区受损的生态 系统及时修复至关重要。目前, 生态修复治理需耗 费大量人力物力, 仅单纯依靠某一责任人的资金来 源修复生态系统难以实现。2014年最高人民法院、 民政部、环境保护部联合发布《关于贯彻实施环境 民事公益诉讼制度的通知》，基于生态修复成本的 双重性，被告承担的生态环境修复费用有可能是天 价的。著名的“泰州污染案”中，一审法院判决污染 企业承担环境的修复费用是1.6亿。污染企业无力支 付, 判决处于一纸空文的状态, 二审法院进行了改 判(吕忠梅和窦海阳, 2017)。哈佛商学院案例库和清 华经管学院中国工商管理案例库共同完成了亿利 资源集团库布其沙漠生态修复项目，该项目实施时 间长达25年，单自然修复部分(不计社会修复成本) 先后投入治沙资金高达30多亿元(吴鹏, 2015)。

生态保护红线的修复费用如前文所述由自然 成本与社会成本组成。生态系统包括自然生态系统 及社会生态系统两方面, 修复自然并不意味着社会 修复也随之自动完成。要彻底修复生态保护红线, 仍需要从自然与社会两方面同时发力。简单地恢复 自然生态环境并不能解决问题, 应清晰认识到存在 的社会问题。社会问题若不能妥善处理, 生态保护 红线的环境问题也就无法从根源上解决。

\section{3 治理责任错乱引发修复主体选择困境}

生态问题的产生有自然因素, 但更多的是人为 因素。发达地区和欠发达地区社会经济发展不平衡 是我国的基本国情, 而这一基本国情的产生是国家 政策或者说是国家发展战略的历史演进的结果。所 以生态保护红线修复机制必须区别对待不同发展 地区和人民的利益, 这是一种解决红线区修复问题 上的缓冲地带和缓和方式。生态修复是一种直接的 自然应对手段, 是从自然修复着手寻找生态保护红 线恢复机制与主要措施, 避免了人类活动造成的负 面影响。发达地区对红线区应当负有生态修复技术 开发和资金资助的义务, 而欠发达地区如中西部红 线区现阶段最重要的是生态保护与可持续发展, 利 用生态修复工程更好地使生态环境得到明显改善, 以协调生态保护之间的矛盾。“先富带动后富” 是国 家战略的庄严承诺, 生态保护红线修复工程中的 投资、援助、补偿、直接赔偿都是国家承诺履行的 过程。
生态保护红线修复机制所追求的目标是恢复 和重建生态系统，使得生态系统能够恢复到均衡状 态。而这种恢复或重建需要多重工程、技术措施，大 量人员投入，成本巨大，更是一个长期的过程。从 权利义务分配正义的角度分析，造成红线区生态系 统受损的资源开发方、资源使用方或是相关产业的 利益链群体, 乃至国家和政府都要承担应尽的责 任。但如何分配这种责任, 需要在具体制度构建层 面进行妥善解决。

\section{生态保护红线修复机制法治化的基本路待}

\section{1 明确预防为主原则}

在上文所述全国首例野生动物保护预防性公 益诉讼案件中，关键在于其“预防性”。原告并没有 科学完整的证据证明水电厂的建设一定会造成绿 孔雀灭绝，但仍可提起环境公益诉讼。预防为主原 则在生态保护红线修复中起到了重要作用，它是指 为了保护环境, 应当采用预防措施, 在遇到严重威 胁生态环境的风险时，不得以缺乏科学充分证据为 由，延迟或不采取符合成本效益的措施。它包含以 下内容: 一是生态保护红线所面临的是潜在的、科 学暂时无法预计的但又关系重大的环境风险; 二是 生态保护红线的环境风险防范对象包含两个方面 - - 环境污染的风险和生态系统破坏的风险，后者 所占比重更大; 三是作为调整对象的风险并不是指 所有的风险，而是不可逆转、极难恢复的环境损害。 生态保护红线涉及到我国生态安全，它的空间不可 置换性和极难恢复性要求在严守与修复过程中遵 循预防为主原则。

生态保护红线适用预防为主原则应当包含以 下几个方面: (1)开展定期评估。《若干意见》第13 条规定，建立红线功能评价指标体系和方法应当从 生态系统格局、功能和质量考虑。对生态保护红线 的定期评估可及时发现了解严重的环境风险，以便 采取必要措施及早预防。(2)逐步推进生态移民。在 有条件的地区应当采取预防措施，逐步推进生态移 民以降低人类活动强度, 减少生态压力。(3)建立监 测网络和监管平台。目前, 结合国务院有关部门生 态环境监管平台(包括大数据、云计算)等信息手段, 强化生态保护红线建设数据集成分析，运用科技手 段及时接收和反馈生态环境信息，预警生态风险。 (4)举证责任倒置。当风险不确定时，应当由资源开 
发者或利用者等承担其行为不会引起生态保护红 线环境损害的举证责任。

\section{2 成立生态保护红线修复专项资金}

《若干意见》规定，应当多渠道筹集生态红线 保护资金，利用市场化、社会化投融资机制，充分 发挥资金合力。不同利益、不同区域的人们对于自 然资源有着自身利益诉求，资源的稀缺性、功能修 复的周期性都使得利益诉求差异发生尖锐且较难 调和的矛盾。这些利益关系总是跟自然资源联系在 一起，体现着对财产利益需求，红线制度中的生态 补偿机制能在不同群体之间达成缓冲。

生态保护红线修复专项资金包含以下几个要 素: (1)专项资金必须以实现生态保护红线修复为目 的，以生态系统服务及其所依附的红线区自然资源 为依托。专项资金以提供生态服务为支持，是伴随 着社会对生态红线功能性保护以及对生态系统重 要性认知的深入而出现的制度性安排。生态系统的 服务并不是凭空出现的, 它依赖于红线区所保护的 特定自然资源，自然资源为生态系统提供着多种功 能并由此使社会受益。(2)专项资金的标准须考虑生 态保护红线的修复成本、生态系统服务价值、日常 管理成本三方面的因素, 是以经济激励为主要特征 的经济环境政策的制度安排。(3)生态系统服务的手 段是行政与市场相结合, 以自愿协商为原则。(4)生 态保护红线修复专项资金具体内容体现为调整人 与自然、人与人之间的紧张关系。自然资源在符合 生态系统健康发展的前提下保障和维持良好状态, 可再生资源能够在满足人们需要的情况下持续供 应，是经济发展的坚实基础。生态保护红线修复问 题是一个巨大的工程，建立生态保护红线专项资金， 必须结合污染者、开发者、政府、社会乃至整个国 家的共同参与才能完成。

\section{3 确定生态保护红线修复主体的顺位}

(1)污染者是红线区修复第一顺位义务主体。污 染者履行直接的修复义务是“污染者付费、受益者 补偿原则”的诠释。依据《环境保护法》规定, 企事 业法人或其他经营者对环境污染、生态破坏负有防 止、减少的义务, 且对其造成的损害应承担法律责 任。该条款虽未明确污染者承担责任的具体方式, 却厘清了责任主体归属。生态修复的个体责任主要 是通过对环境侵权进行界定, 从而确定污染发生后 实施者应负的法律义务及责任。然而, 鉴于红线区
一旦发生污染结果往往是不可逆转、极难恢复的。 即使可以修复，事后修复成本极高，因此预防性修 复义务便成为日后保护生态红线的重点方向，在制 定法律、设定规则时，应事先将生态修复义务与环 境开发进行绑定，使修复义务成为社会主体开发、 利用环境资源的前提条件，通过建立环境保证金制 度可有效预防损害发生。行政制裁乃至刑事责任多 为事后追责，事前与事后防治措施互相配合。

(2)资源开发者、利用者及相关产业利益链群体 为第二义务承担主体。资源的开发者与利用者在某 些时候是相互对应而存在。资源的开发方享有资源 买卖利润，而利用者享有资源使用获取的间接利润， 例如发电获得的利润。由此, 这种直接利润与间接 利润的取得就是不同的利益获取方式，他们权利享 有的程度和范围也是不同的，对此，义务的承担方 式也应有所不同。开发方应当直接从利润中核算红 线区修复所需的相应数额，利用方则应当通过资源 转让价格承担相应的生态修复义务。而对于相关产 业利益链群体可以通过直接参与生态修复工程、开 发生态修复技术、投资生态修复产业等形式承担相 应社会义务。也就是说资源利用的主体与资源直接 开发者都应当直接或间接参与生态红线的修复，保 障生态修复工程运行。许多情况下资源开发方也同 样是利用方, 这是权利竞合基础上的义务竞合, 须 承担相对更多的义务。此外, 生态发展区虽然是直 接受益方，但理应承担仅次于污染者、利用者义务 的生态修复义务。资源的获益群体积极履行修复生 态环境的义务, 帮助资源开发区重新获得可持续发 展的机会。

(3)国家与地方政府是生态保护红线修复责任 的补充主体。有学者认为, 我国现有的环境污染赔 偿责任机制主要适用《侵权责任法》的相关规定，对 受害人的人身权和财产权进行赔偿。而对环境损害 的污染治理和生态恢复责任一直由国家买单，这既 不公平又不合理。生态修复义务是环境污染的责任 人和地方政府应共同承担的法定义务。当企业等社 会主体的行为造成生态破坏时，根据污染者负担原 则，其应履行生态修复义务; 当某区域环境质量全 面性恶化，对当地人们的身体健康及财产权益造成 普遍威胁时，当地政府应承担治理环境污染、改善 生态质量的重担。但是，两者的责任各有分工侧重， 社会主体主要是为自身的行为买单, 而政府是在个 
人责任无法厘清, 或责任主体缺位, 或丧失履行能 力的情况下承担责任。企业治理污染的责任源自该 行为给予生态环境造成的损害, 而政府的污染治理 责任是源于国家保护义务的“樂底”责任。

“社会制度的运行目的就是将人们组织起来实 现有序的生活状态，并在实践中产生利益和负担进 行分配” (Rawls, 2009)。“不在于对具有 “反社会”行 为的制裁, 而在于对危险事故所致之不幸损害之合 理分配, 即所谓分配正义”(钭晓东, 2012)。生态保护 红线修复主体的确定是整个制度构架的难点也是 关键点。生态保护红线修复过程的权利义务承担应 当是相互对应的，根据法律分配正义价值要求，广 泛的承担主体并不意味着权利义务的平均分配，而 是根据获得利益多少, 依据市场的需求进行直接的 义务承担，或者间接的义务再分配。

\section{参考文献}

Dou XD (2012) On the reorganization of environmental legal responsibility mechanism. Law Review, (1), 125-142. (in Chinese) [钭晓东 (2012) 论环境法律责任机制的重整. 法学评论, (1), 125-142.]

Gao JX (2015) Exploring the delineation and supervision of ecological protection redlines in China. Biodiversity Science, 23, 705-707. (in Chinese) [高吉喜 (2015) 探索我 国生态保护红线划定与监管. 生物多样性, 23, 705-707.]

Liu D, Lin NF, Zou CX, You GY (2015) Development of foreign ecological protected areas and linkages to ecological protection redline delineation and management in China. Biodiversity Science, 23, 708-715. (in Chinese with English abstract) [刘冬, 林乃峰, 邹长新, 游广永 (2015) 国外生 态保护地体系对我国生态保护红线划定与管理的启示. 生物多样性, 23, 708-715.]

Lv ZM, Dou HY (2017) Empirical analysis of remediation of ecological environment responsibility. Chinese Journal of Law, (3), 125-142. (in Chinese with English abstract) [吕忠 梅, 窦海阳 (2017) 修复生态环境责任的实证解析. 法学 研究, (3), 125-142.]

Rawls J (translated by He HH, He BG, Liao SB) (2009) Theory of Justice, p. 51. China Social Sciences Press, Beijing. (in Chinese) [何怀宏, 何包钢, 廖申白 (译) (2009) 正义论. 中国社会科学出版社, 北京.]

Shi YJ, Wu XJ (2016) Discussion on the standardization of the concept of ecological red line. Journal of South-Central University for Nationalities, 36(3), 149-152. (in Chinese) [施业家，吴贤静 (2016) 生态红线概念规范化探讨. 中 南民族大学学报, 36(3), 149-152.]

Shen Y, Liu TK, Zhou P (2017) Theoretical analysis and strategies of natural ecological space use control. China Land Sciences, 31(12), 18-22. (in Chinese with English abstract) [沈悦, 刘天科, 周璞 (2017) 自然生态空间用途 管制理论分析及管制策略研究. 中国土地科学, 31(12), 18-22.]

Wu P (2013) The primary research about ecological restoration legal system. Hebei Law Science, 31(5), 171-174. (in Chinese with English abstract) [吴鹏 (2013) 生态修复法 制初探. 河北法学, 31(5), 171-174.]

Wei X (2016) A preliminary study on the basic categories of ecological restoration system. Journal of Gansu Political Science and Law Institute, (1), 5-6. (in Chinese) [魏旭 (2016) 生态修复制度基本范畴初探. 甘肃政法学院学报, (1), 5-6.]

Wu P (2015) Misunderstanding and correction of ecological restoration system by judicial interpretation of the Supreme Court. Journal of China University of Geosciences, (4), 49-52. (in Chinese) [吴鹏 (2015) 最高法院司法解释对生 态修复制度的误解与矫正. 中国地质大学学报, (4), 49-52.]

Yang ZK (2017) Probe into attributes of the ecological red line as a legal system. Journal of Nanjing Tech University (Social Science Edition), 16(3), 57-63. (in Chinese with English abstract) [杨治坤 (2017) 生态红线法律制度的属 性探析. 南京工业大学学报(社会科学版), 16(3), 57-63.]

Zou CX, Wang LX, Liu JH (2015) Classification and management of ecological protection redlines in China. Biodiversity Science, 23, 716-724. (in Chinese with English abstract) [邹长新, 王丽霞, 刘军会 (2015) 论生态保护红 线的类型划分与管控. 生物多样性, 23, 716-724.]

(责任编委: 薛达元 责任编辑: 时意专) 